\title{
DOUBLE ENANTIOSELECTIVE ESTERIFICATION OF RACEMIC ACIDS AND ALCOHOLS BY LIPASE FROM Candida cylindracea
}

\author{
Pei-Yeh Chen, Shih-Hsiung $W^{*}$ and Kung-Tsung Wang \\ Institute of Biological Chemistry, Academia Sinica \\ and \\ Graduate Institute of Biochemical Sciences, \\ National Taiwan University \\ P.O.BOX 23-106, Taipei, Taiwan, ROC
}

\section{SUMMARY}

Doubly enantioselective lipase-catalyzed esterification of racemic acids and alcohols was proceeded in $n$-hexane. The enantioselectivities of the lipase toward both of racemic substrates were affected reciprocally. It showed that the active site of the lipase was quite flexible.

\section{INTRODUCTION}

It has been found that lipase could convert a carboxylic acid and an alcohol to an ester in organic solvent. For a chiral acid or alcohol, the esterification was highly stereoselective (Kirchner et. al, 1985; Klibanov, 1990; Chen et al. 1987; Sonnet, 1987; Wong, 1989; Sih and Wu, 1989). It is believed that lipases contain two binding sites; one for acid moiety and the other for alcohol moiety. Therefore, double enantioselection of esterification by lipases with racemic acids and alcohols as substrates has been proposed (Chen and Sih, 1989). Until now, a couple of efforts have been done to disclose the double enantioselectivity of the lipase in organic solvent. Holmberg and Hult (1992) found that differently chiral alcohol can affect Candida lipase to choose R-form or S-form acid as its preferred substrate in the esterification. Theil et al. (1992) described doubly enantioselective transesterification between a meso-diol and a racemic carboxylic ester by $C$ andida lipase. Here we simultaneously use racemic 2-phenoxypropionic acids and racemic alcohols for the double enantioselection of esterification catalyzed by lipase from Candida cylindracea and the products were analyzed to determine the enantioselectivities of both binding sites in the lipase.

\section{MATERIALS AND METHODS}

Commercial extracellular lipase (E.C.3.1.1.3) from Candida cylindracea was obtained from Sigma, US. The specific activity was 500 units $/ \mathrm{mg}$ solid and 2940 units/mg protein. DL-sec-phenethylalcohol, DL-1-phenyl-1-propanol, DL-2phenyl-1-propanol, DL-2-(2.4-dichlorophenoxy)propionic acid, DL-2-(2chlorophenoxy)propionic acid, DL-2-(4-chlorophenoxy)propionic acid and DL- 
2-phenoxypropionic acid and DL-2-(3-chlorophenoxy)propionic acid were purchased from Aldrich, US. The Chiral-2 column was purchased from Macherey-Nagel, Duren, Germany. The Chiralcel OB column was the product of Daicel Chemical Industries, Lid. (Japan). All solvents used were purchased from Alps Chem Co. Lid, Taiwan.

Esterification reactions by lipase:

A solution of racemic acid $(3 \mathrm{mmol})$ and racemic alcohol $(3 \mathrm{mmol})$ in $6 \mathrm{ml}$ of $n$-hexane containing $50 \mu \mathrm{l}$ of $0.1 \mathrm{M}$ potassium phosphate buffer ( $\mathrm{pH} 7.65$ ) and $10 \mu 1$ of $1 \mathrm{mM} \mathrm{CaCl} 2$ was stirred and $200 \mathrm{mg}$ of the lipase was added portionwise to the solution. The reaction at room temperature was monitored by TLC with $n$ hexane : ethyl ether $(4: 1, v / v)$ as developing solvent.

Once the ester products reached to some extent, the reaction mixture was filtered to remove the enzyme. The filtrate was extracted with a equal volume of $0.1 \mathrm{M} \mathrm{Na} \mathrm{CO}_{3}$ for obtaining remaining acids. Organic layer and aqueous layer were collected separately. The aqueous layer was extracted thrice with $n$ hexane, then adjusted to $\mathrm{pH} 3$ with conc. $\mathrm{HCl}$, and extracted twice with ethyl ether. Remaining acid in ether solution was treated with diazomethane to obtain its methyl ester for determining the enantiomeric excess by chiral HPLC. The organic layer was dried, applied to a silica gel column, and eluted with $n$-hexane : ethyl ether (12:1, v/v) to separate product ester and remaining alcohol.

Preparation of reacied acids and alcohols:

The isolated product ester was dissolved in $1 \mathrm{ml}$ acetone. To which $3 \mathrm{ml}$ of 1 $\mathrm{N} \mathrm{NaOH}$ was added, then the mixture was shaked vigorously. After $1 \mathrm{~h}$, the reaction mixture was extracted thrice with $n$-hexane for obtaining reacted alcohol. The aqueous layer was adjusted to $\mathrm{pH} 3$ by conc. $\mathrm{HCl}$, and then extracted twice with ethyl ether. The collected ethyl ether was treated with diazomethane to give the methyl ester of reacted acid.

Determination of the enantiomeric excess (ee) of remaining acids remaining alcohols, reacted acids and reacted alcohols :

The ee of methyl esters of remaining and reacted acids were determined by HPLC on a chiral-2 column with $n$-heptane : isopropanol : tetrafluoroacetic acid (100: $0.02: 0.05, \mathrm{v} / \mathrm{v} / \mathrm{v}$ ) as mobile phase, flow rate : $0.5 \mathrm{ml} / \mathrm{min}$, detected at UV $254 \mathrm{~nm}$.

The ee of remaining and reacted alcohol obtained were determined by HPLC on a chiralcel OB column with $n$-hexane : isopropanol $(92: 8, v / v)$ for DLsec-phenethylalcohol, $(98: 2, \mathrm{v} / \mathrm{v})$ for DL-1-phenyl-1-propanol, and $(100: 1, \mathrm{v} / \mathrm{v})$ for DL-2-phenyl-1-propanol as mobile phase, flow rate : $0.5 \mathrm{ml} / \mathrm{min}$, detected at UV $254 \mathrm{~nm}$.

Calculation of conversion and enantiomeric ratio.

Conversion (C) was calculated by the following equation:

$$
\mathrm{C}=\mathrm{ee}_{\mathrm{s}} /\left(\mathrm{ee_{s }}+\mathrm{ee} \mathrm{p}\right)
$$

The subscripts $s$ and $p$ refer to substrate and product respectively. Both enantiomeric ratios(E) for acid-binding site and alcohol-binding site were calculated by the method of Chen et al. (1982):

$$
\begin{gathered}
E=\ln \left[(1-C)\left(1-e e_{s}\right)\right] / \ln \left[(1-C)\left(1+e e_{s}\right)\right] \\
\text { or } \\
E=\ln [1-C(1+e e p)] / \ln [1-C(1-\text { eep })]
\end{gathered}
$$

\section{RESULTS AND DISCUSSION}

The results of the doubly enantioselective reactions were summarized in Table 1. From the results. It appears that the chlorine substitute in the phenyl 
TABLE 1. Enantioselective esterification of racemic acid and racemic alcohol by lipase

\begin{tabular}{|c|c|c|c|c|}
\hline SUBSTRATE & \multirow{2}{*}{$\begin{array}{c}\text { Time } \\
(h r)\end{array}$} & \multirow{2}{*}{$\mathrm{C}(\%)$} & \multirow{2}{*}{$E_{\text {acid }}$} & \multirow{2}{*}{$\mathrm{E}_{\mathrm{alcohol}}$} \\
\hline acid alcohol & & & & \\
\hline & 113 & 32 & 108 & 5.2 \\
\hline & 122 & 21.5 & 35.6 & 13.6 \\
\hline & 116 & 59.7 & 6.4 & 1.0 \\
\hline & 122 & 15.3 & 12.5 & 10.4 \\
\hline & 20 & 6.3 & 2.2 & 3.2 \\
\hline & 116 & 34.5 & 10.1 & 1.0 \\
\hline & 30 & 7.2 & 3.8 & 3.3 \\
\hline & 122 & 7.0 & 3.6 & 7.5 \\
\hline & 116 & 12.1 & 3.7 & 1.5 \\
\hline & 20 & 2.0 & 2.6 & 11 \\
\hline & 116 & 7.9 & 2.1 & 1.6 \\
\hline & 116 & 35.7 & 15.4 & 1.1 \\
\hline
\end{tabular}


ring of 2-phenoxypropionic acid derivatives has great influence on the enantioselectivity. In general, 2-(2,4-dichlorophenoxy)propionic acid and 2-(2chlorophenoxy)propionic acid, which contain the chlorine substitute in the ortho position of phenyl ring, have low enantioselectivity in the enzymatic reaction, even with different alcohol substrates.

The primary alcohols tested show lower enantioselectivity than secondary alcohols in the enzymatic reaction. DL-2-(4-chlorophenoxy) propionic acid and DL-2-phenoxypropionic acid show higher $E$ with DL-secphenethylalcohol, but have lower $E$ with DL-1-phenyl-1-propanol. Similarly, DL-1-phenyl-1-propanol esterified with DL-2-(4-chlorophenoxy)propionic acid and DL-2-phenoxypropionic acid have different $E$ value(13.6 and 3.2 , respectively). DL-sec-phenethylalcohol esterified with DL-2-phenoxypropionic acid and DL-2-(2,4-chlorophenoxy)propionic acid also have different $E$ value, 10.4 and 3.3 , respectively. Thus the enantioselectivities of racemic acids and racemic alcohols are not only affected by their own structure. but also by the structure of their counterpart substrates, implying that the two binding sites of the lipase have some correlation.

Several conclusions deserve to be described : (a) For the substrates tested, primary alcohol generally has higher reaction rate, but less enantioselectivity than secondary alcohols. (b) For 2-phenoxypropionic acid derivatives, substitutions in the aromatic ring strongly influence the reaction rate and enantioselectivity. (c) The tertiary structure of the lipase is quite flexible (Wu et. al, 1991);, different alcohols give different enantioselectivity for the same acid and vice versa. These results are consistent with that of the previous report (Holmberg and Hult, 1992).

\section{REFERENCES}

Chen, C.S., Fujimoto, Y., Girdaukas, G and Sih, C.J. (1982) J. Am. Chem. Soc., 104, 7294-7299.

Chen, C. S. and Sih, C. J. (1989) Angew. Chem. Int. Ed. Engl. 28, 695-707.

Chen, C.S., Wu, S. H., Girdaukas, G and Sih, C.J. (1987) J. Am. Chem. Soc., 109, 2812. 2817.

Holmberg, E. and Hult, K. (1992) Biocatalysis, 5, 289-256.

Kirchner, G., Scollar, M.P. and Klibanov, A.M. (1985) J. Am. Chem. Soc., 107, 70727076.

Klibanov, A. M. Acc. Chem. Res. (1990) 23, 114-120.

Sih, C. J. and Wu, S. H. (1989) Topics Stereochem. 19, 63-125.

Sonnet, P. E.(1987) J. Org. Chem. 52, 3477-3479.

Theil, H., Kunath, A. and Schick, H. (1992) Tetrahedron Lett, 33, 3457-3460.

Wong, C. H. Science. (1989) 244, 1145-1152.

Wu, S.H., Chu, F.Y. and Wang, K.T. (1991) BioMed. Chem Lett, 1, 339-342. 